\title{
Green Downstream Processing by Using Hydrothermal Extraction for Recovering Flavonoid, Phenolic, and Antioxidant Activity from Moringa
}

\author{
${ }^{a}$ Ghusrina Prihandini*, ${ }^{\text {aPaih Purnama Alam }}$ \\ aDepartment of Chemical Engineering, Politeknik Negeri Bandung, Bandung 40012, Indonesia
}

Received 21 October 2021; accepted 5 March 2021

\begin{abstract}
Well known as rich in phenolic compounds, Moringa oleifera mature leaf extract shows significant antioxidant activity both in vitro and in vivo. It has been widely used in the cosmetic, medicine, and functional food sector. Hydrothermal extraction is one of the green environmentally friendly methods that fit M. oleifera feedstock for recovering natural antioxidants, namely flavonoid, phenolic, and antioxidant activity. In this study, three parameters were used: sample-solvent ratio, running a temperature, and extraction time. Flavonoids were evaluated by colorimetry of hydrazine 2,4dinitrophenyl, whereas phenolics were measured by using tannic acid reacting with Folin ciocalteu reagent. DPPH measured antioxidant activity. The optimum result was obtained at 15 minutes with $140 \mathrm{OC}$ for total flavonoid content (TFC) $18.98 \mathrm{mg} / \mathrm{g}$ whereas $170 \mathrm{OC}$ for total phenolic content (TPC) and antioxidant activity $48.73 \mathrm{mg}$ tanat acid/dried extract; $44.76 \mathrm{mg} / \mathrm{L}$ respectively.
\end{abstract}

\section{KEYWORDS}

Biomass

Extraction

Environmentally friendly

Natural antioxidant

\section{INTRODUCTION}

Moringa oleifera is widely used as a nutrition supplement to help malnutrition and its harmful effects ${ }^{1}$. Moreover, M oleifera is claimed as a new source of food in China. High phenol and flavonoid content making M. oleifera as a source of antioxidant activity both in vivo and in vitro 2 3. M. oleifera, exclusively at the leaf, having the highest phenol and antioxidant activity content than root, stem, bark, and seed ${ }^{4}$. Nowadays, M. oleifera extract is widely applicable in medicine, nutrition supplement, cosmetics ${ }^{5}$. Several extraction methods have been studied for recovering phenolic and flavonoid compounds from M. oleifera. Many liters of volatile organic solvent, including methanol, ethanol, chloroform, and acetone, were utilized to extract these compounds. However, those extractions still in debate about using a toxic solvent that making harmful to the environment. The sophisticated method such as ultrasonic-assisted extraction (UEA), supercritical fluid extraction, microwave-assisted extraction (MAE). The supercritical extraction offered high yield and clean extract, but at this temperature, the phenolic and flavonoid compounds may be destroyed. This extraction method is not suitable for polar compounds. The UEA also provides high yield, clean extract, and short time extraction, but too many undesired 
compounds carried at extract that making hard and long steps in separation process ${ }^{2}$. The hydrothermal extraction in the subcritical situation, the most effective method to extract flavonoids and phenolics from M. oliefera, has been proved. This method was claimed as natural, eco-friendly among others ${ }^{8} 9$ 10. Water could extract polar compounds or decompose lignin cellulose at this state, becoming valuable compounds such as organic acid, aromatic, protein ${ }^{11}$ and applicable for extract phenolic compounds ${ }^{12}$. This method to be an option due to only utilizing water as a solvent. Hence making the yield product more fit to edible food.

In this study, the extraction of flavonoid, phenolic compound, and antioxidant activity from M. oleifera mature leaves using hydrothermal extraction at a subcritical state was carried at a mini stainless steel reactor batch would be discussed.

\section{MATERIALS AND METHODS}

\section{Materials}

Pretreatment M. oleifera leaves were separated from ranting. Then chopped and dried in the open air under the sun. The dried leaves were grinding into powder for maximizing surface area. Powder kept at vacuum storage at freeze temperature. Reagent Ciocialteu and any chemical were purchased from a commercial source.

\section{Maceration}

Maceration, the classical extraction method used, is comparable to hydrothermal extraction. This method using ethanol as a solvent for 72 hours followed earlier study 13. Ratio 1:6 dried powder / solvent. Filtration with vacuum pump was done after maceration ended. The wet extract was collected and dried in the open air.

\section{Hydrothermal extraction}

The hydrothermal extraction was carried at $110 \mathrm{OC}-230 \mathrm{OC}$, ranging from reaction time 5-20 minutes. Ratio dried powder: water $1 / 6$ (gr/ml) was poured in a mini tube stainless steel reactor and heated into a furnace. The pressure was kept at $7 \mathrm{MPa}$. After the end reaction time, the reactor was shocked into the cold water of a sudden to stop the reaction. The extract was collected with a vacuum pump and kept in a $50 \mathrm{~mL}$ bottle. The bottles are kept in the freezer and equipped with a black seal to protect the sample from light to prevent degradation when analyzed 2.

\section{Flavonoid Analysis}

Flavonoid analysis utilized 2,4Dinitrophenylhydrazine Colorimetric. The principal basis of this method is that 2,4-dinitrophenylhydrazine reacts with keton and aldehid, becoming 2,4dinitrophenylhydrazones. Hence, flavones were obtained, whereas flavonols and isoflavone with double-bound C2-C3 could not react with 2,4-dinitrophenylhydrazine. Meanwhile, hydrazone that is having a maximum of $495 \mathrm{~nm}$ was chosen as reaction wavelength. Sample $20 \mathrm{mg}$ was 


\section{G. PRIHANDINI ET.AL}

soluble in methanol to make variant concentrations. $1 \mathrm{~mL}$ of each concentration react with $2 \mathrm{~mL}$ reagent 2,4-dinitrophenylhydrazine $1 \%$ and methanol at 50 oC for 50 minutes. After cooling down at room temperature, the solution was added by $5 \mathrm{~mL}$ potassium hydroxide in $70 \%$ methanol and incubated for 2 minutes at room temperature. About $1 \mathrm{~mL}$ was taken from the solution and react with $5 \mathrm{~mL}$ methanol. Then centrifuge at 1000 rpm to extinguish the suspended solid. When supernatant was obtained, then diluted becomes $25 \mathrm{~mL}$. Analyzed at $495 \mathrm{~nm}$ to find out the quantity of flavonoid content14.

\section{Phenolic Analysis}

Initially make tannat acid standard curve with various concentrations, ranging from 10-100\%. Each concentration was added with $0.5 \mathrm{~mL}$ Folin ciocalteu reagent, adding $2 \mathrm{~mL} \mathrm{Na2CO} 37.5 \%$, and then kept in the dark place at room temperature. UV-Vis was utilized to measure phenolic compounds' content with absorbance 779 wavelength 15 . Phenol analysis was carried with $0.1 \mathrm{~mL}$ extract diluted in methanol and demin water until $2 \mathrm{~mL}$. Then, followed the steps standard curve. Results were shown in mg tanat acid/ mg extract.

\section{Determine antioxidant activity}

The standard solution was made in $10 \mathrm{mg}$ vitamin $\mathrm{C} / 100 \mathrm{~mL}$ and diluted into 2, 4, 6, $8 \mathrm{mg} / 100$ $\mathrm{mL}$. Six reaction tubes were filled with o,1 $\mathrm{mL}$ mixture and diluted into $2 \mathrm{~mL}$ with methanol. Each reaction tube was added $2 \mathrm{~mL}$ of $35 \mu \mathrm{g} / \mathrm{mL}$ DPPH (1,1-diphenyl-2picryhidrazil) and kept at room temperature in a dark place for 30 minutes. UV-vis was set at 517 wavelengths, then measured absorbance of each solution, and the standard curve was obtained. The same steps were carried out for evaluating sample extract. The principle of evaluating antioxidant activity utilizing DPPH method when DPPH solution is mixed with compounds that donate hydrogen atoms, DPPH is reduced and loses its purple color.

\section{RESULTS AND DISCUSSION}

\section{Hydrothermal process}

M. oleifera were extracted at hydrothermal extraction under subcritical state $110 \mathrm{OC}-230 \mathrm{OC}$. Combination temperature and reaction time precisely bring out optimum yield and bioactive compounds (flavonoid, phenolic). The obtaining yields were described in Figure 1. 


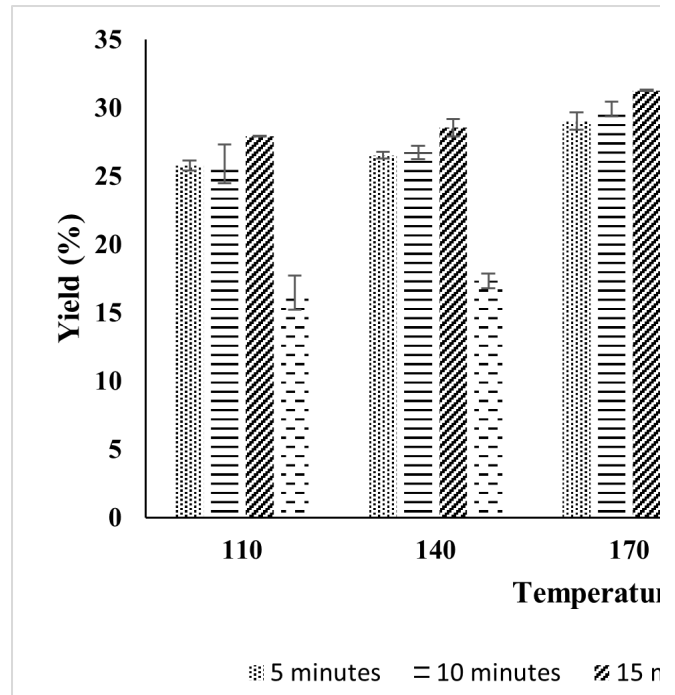

(a)

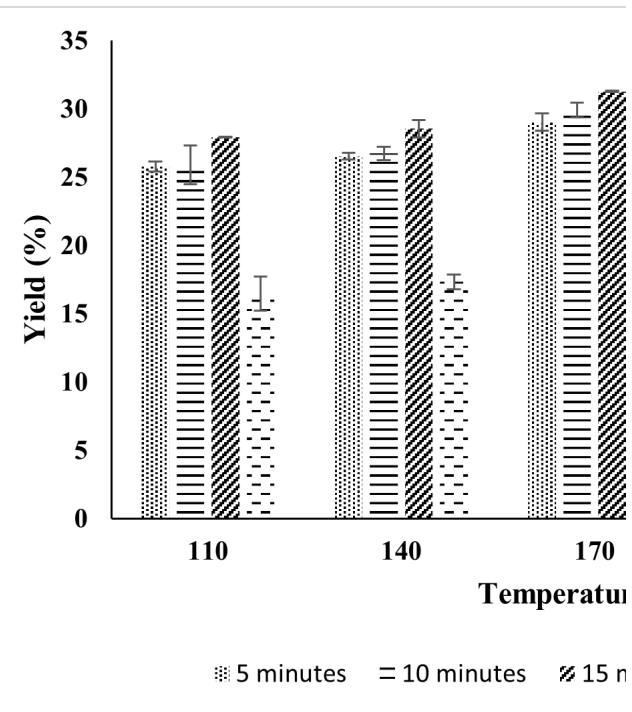

(b)

Figure 1. Fluid Temperature and Reaction Time on Yield Effect

When temperature and pressure are set, the yield always increases first with extended reaction time, then decreases slowly. However, different reaction times are corresponding to the highest yield at different reaction time temperatures. With the extension reaction time, the more prolonged contact between sample with water, and more ions $\mathrm{H}_{3} \mathrm{O}^{+}$dan $\mathrm{OH}^{-}$are released at that subcritical state ${ }^{16}{ }^{17}$. The highest yield was obtained at $17 \mathrm{O}^{\circ} \mathrm{C}$ for 15 minutes at the hydrothermal extraction method.

\section{Total Flavonoid Compounds}

In the present study, total flavonoid compounds (TFC) of the hydrothermal extraction were expressed as $\mathrm{mg} / \mathrm{g}$ sample. Figure 2 show that there were no significant differences about temperature $1400 \mathrm{C}$ and $1700 \mathrm{C}$. However, the lower temperature is more acceptable due to flavonoids not resistant to high temperatures. 


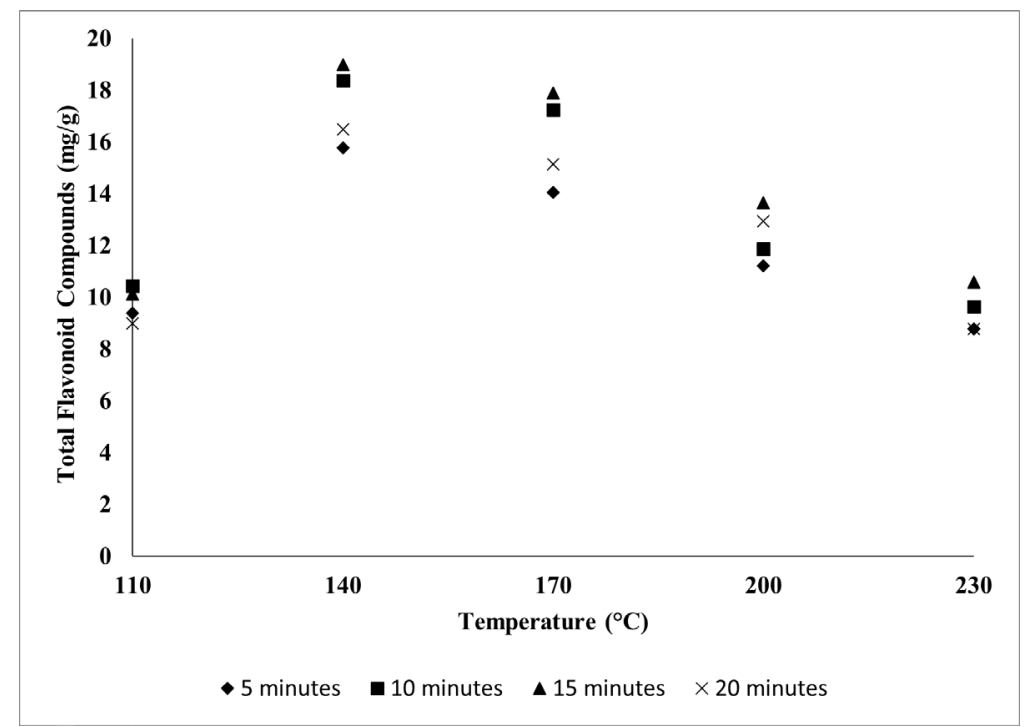

Figure 2. Temperature and Reaction Time Effect on Flavonoid Compounds

It was proofed that flavonoid content at $1700 \mathrm{C} ; 17.8 \mathrm{mg} / \mathrm{g}$ sample little much lower even though highest yield obtained. On the other hand, at $1400 \mathrm{C}$, the $18.98 \mathrm{mg} / \mathrm{g}$ sample was the highest flavonoid content, although the yield content not high enough. Several reports demonstrated the different results of total flavonoid content M. oleifera leaves from other extraction methods. Sreelatha and Padma reported that mature leaves have potent flavonoids was $27 \mathrm{mg} / \mathrm{g}$ sample than those of tender leaves. As reported [Rodriguez Perez] before, the predominant group of phenolics compounds in M. oleifera leaves was the flavonoid group with the most predominant kaempferol and quercetin derivatives.

\section{Total Phenolic Compounds}

In this study, total phenolic compounds (TPC) of M. oleifera extracts were expressed as mg tanat acid/ mg dried sample. Phenolic compounds are extracted by hydrothermal extraction using subcritical water temperatures consisting of phenolic compounds and other non-phenolic compounds. Due to this study not characterizing particular phenolics, therefore, they called total phenolic compounds. The highest total phenolic compound was found $48.733 \mathrm{mg}$ tannat acid/ mg dried sample at $1700 \mathrm{C}$ for 15 minutes. Temperature higher than $1700 \mathrm{C}$ is not allowed due to phenolic compounds gradually degrade. The data were shown in Figure 3. 


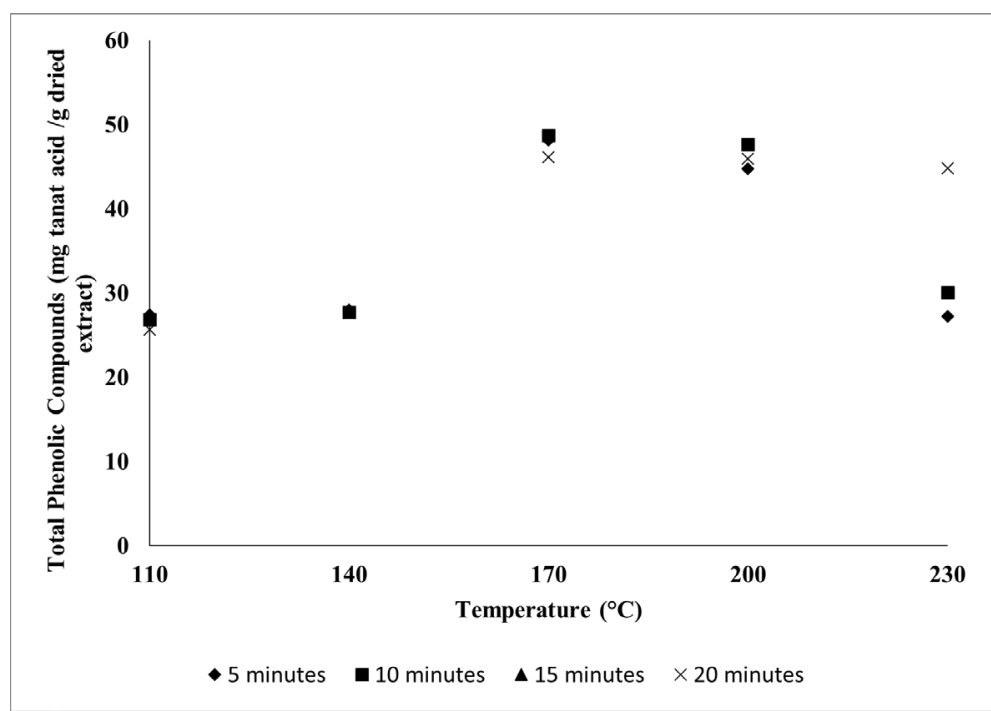

Figure 3. Temperature and Reaction Time Effect on Phenolic Compounds

\section{Total Phenolic Compounds}

Antioxidant activity of M. oleifera leaves extracts were described as mg Vitamin C/L Several studies reported that exert antioxidant activity by ascorbic acid at hot water tea extract ${ }^{18} 19$.

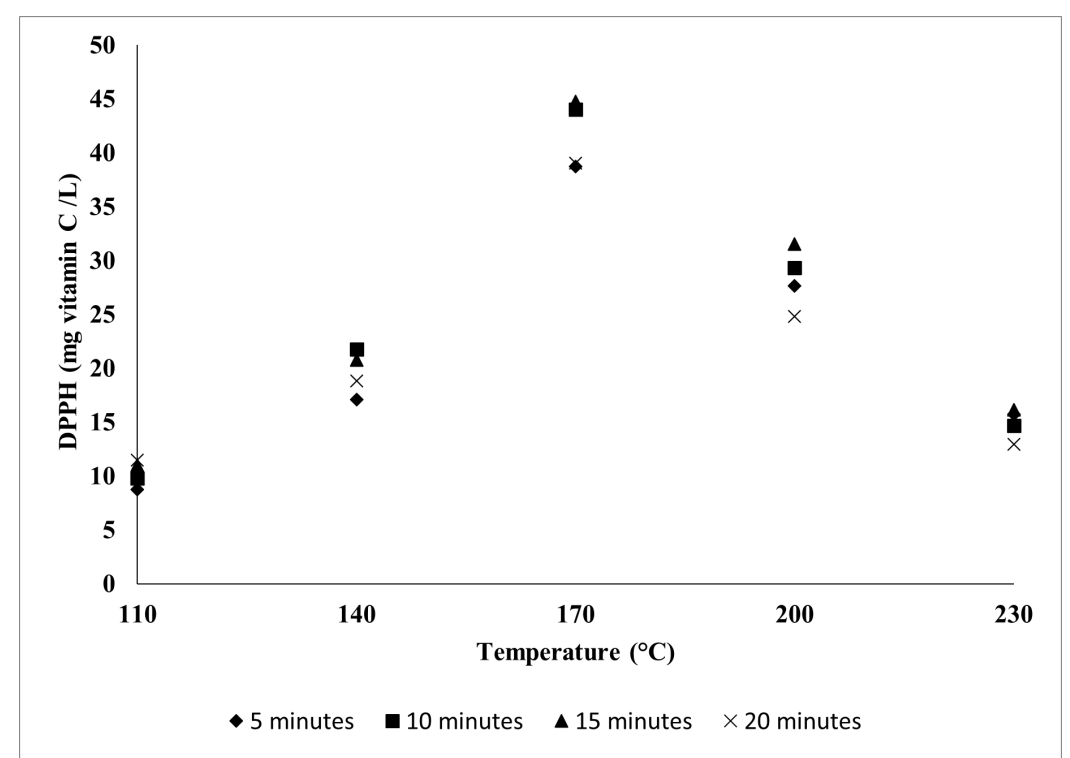

Figure 4. Temperature and Reaction Time Effect on Antioxidant Activity

The result described in Figure 4 shows increasing temperature and reaction time followed by increasing DPPH content. However, increasing too much temperature impact decreasing DPPH content. It could be inferred that free radical scavenging activity through proton donating ability in DPPH assay and the M. oleifera antioxidant activity leaves extract could be an excellent 


\section{G. PRIHANDINI ET.AL}

reductone. The optimum conditions in $1700 \mathrm{C}$ for 15 minutes also, with $44.76 \mathrm{mg}$ vitamin C/L. Extract with high TFC, and TPC content also promoted high DPPH scavenging activity.

\section{Maceration}

Maceration with various ethanol concentrations was utilized compared to the new method, hydrothermal extraction, by using water at subcritical temperature to substitute organic solvent. Maceration carried for 72 hours followed previous research ${ }^{13}$. However, water is still used as the mixture. Utilization water as a mixture of ethanol because of its polarity. Hence, reduce the amount of organic solvent. Effect of water mixture on yield, TFC, TPC, and antioxidant activity can see in Figure 5.

From Figure 5 could be seen that the higher the ethanol concentration, the higher yield obtained. On the other hand, pure water collected tiny yield, flavonoid, phenolic and antioxidant activity. This is perfectly natural, considering there is no physical treatment nor chemical addition. The highest yield results, TPC, TFC, and antioxidant activity, were obtained at 35.92\%; $54.5 \mathrm{mg}$ tannat acid/g dried extract; $15.9 \mathrm{mg} / \mathrm{g} ; 53.5 \mathrm{mg}$ vit C/L successively. Those results were higher than hydrothermal extraction. However, hydrothermal extraction gave more benefits such as escalated penetration from solvent into powder particles, reduced extraction time, and environmentally friendly.

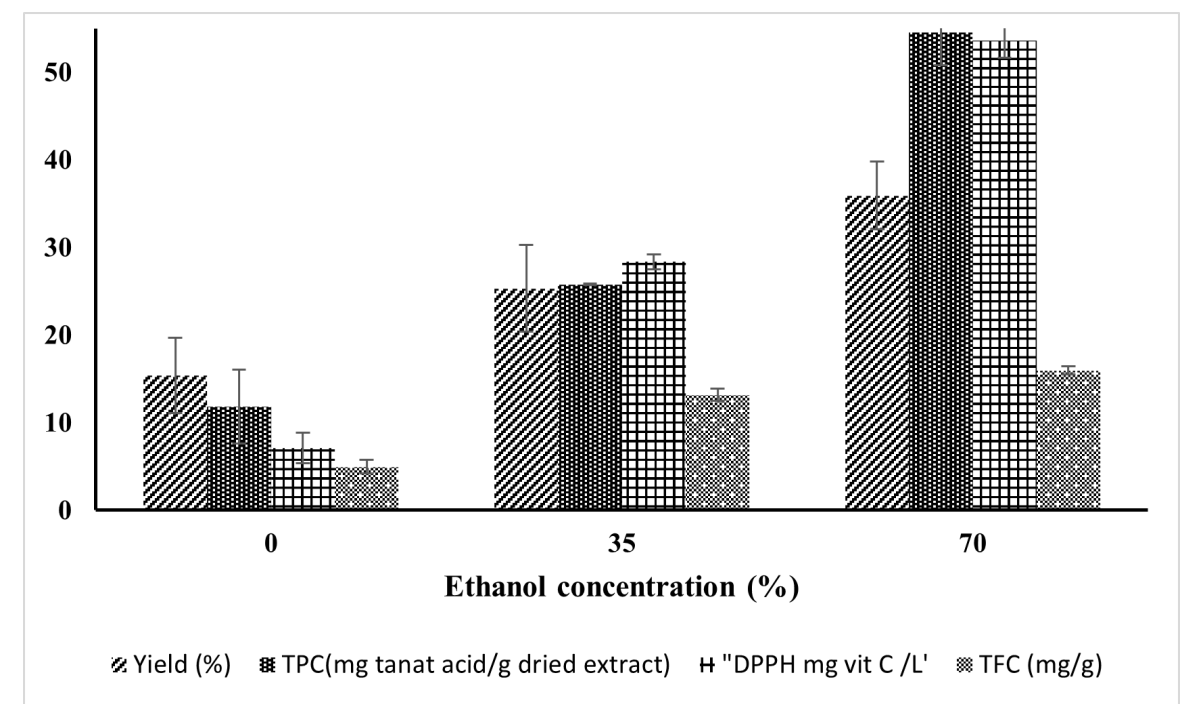

Figure 5. Effect of Ethanol-Water Mixture on Yield, TPC, TFC, and Antioxidant Activity

\section{CONCLUSION}

Hydrothermal extraction with water at subcritical temperature and pressure as a natural solvent to substitute organic solvent was proofed as green downstream processing to obtain high yield extract that corresponds to high flavonoid, phenolic and antioxidant activity in a quick way. However, because flavonoids and phenolics are valuable compounds susceptible to temperature, it is necessary to characterize them. 


\section{REFERENCES}

L. Gopalakrishnan, K. Doriya, D. S. Kumar, Food Sci. Hum. Wellness 5 (2016) 49-56.

Rodriguez-Perez, J. Supercrit. Fluids (2016).

C. Rodríguez-Pérez, R. Quirantes-Piné, A. Fernández-Gutiérrez, A. Segura-Carretero, Ind. Crops Prod. 66 (2015) 246-254.

M. Prabakaran, S. H. Kim, A. Sasireka, M. Chandrasekaran, I. M. Chung, Food Biosci. 26 (2018) 2329.

X. Coz-Bolaños, R. Campos-Vega, R. Reynoso-Camacho, M. Ramos-Gómez, G. F. Loarca-Piña, S. H. Guzmán-Maldonado, Ind. Crops Prod. 118 (2018) 95-101.

N. U. Karim, U. S. A. A. Siddiq, M. R. M. Razak, M. K. M. Zainol, M. I. Abdullah, Ital. J. Food Saf. 7(2018) $153-157$.

G. W. Vongsak B, Sithisarn P, Mangmool S, thongpraditchote S , Wongkrajang Y, Crop. Prod. (2012).

Wahyudiono, S. Machmudah, M. Goto, Eng. J. 17 (2013) 1-12.

S. Machmudah, Wahyudiono, H. Kanda, M. Sasaki, M. Goto, Eng. J. 19 (2015) 25-44.

P. P. Singh, M. D. A. Saldaña, Food Res. Int. 44 (2011) 2452-2458.

G. Y. Zhu, X. Zhu, X. L. Wan, Q. Fan, Y. H. Ma, J. Qian, X. L. Liu, Y. J. Shen, J. H. Jiang, J. Anal. Appl. Pyrolysis 88 (2010) 187-191.

L. He, X. Zhang, H. Xu, C. Xu, F. Yuan, Ž. Knez, Z. Novak, Y. Gao, Food Bioprod. Process. 90 (2012) 215-223.

B. Vongsak, P. Sithisarn, S. Mangmool, S. Thongpraditchote, Y. Wongkrajang, W. Gritsanapan, Ind. Crops Prod. 44 (2013) 566-571.

D. Nagy, M. and Grancai, .. Pharm. (1996) 100-101.

G. Q. Pothitirat W, Chomnawang MT, Suphabbol R, Fisioterapi 80 (2009) 442-447 (2010) 2033-2038.

I. Sereewatthanawut, S. Prapintip, K. Watchiraruji, M. Goto, M. Sasaki, A. Shotipruk, Bioresour. Technol. 99 (2008) 555-561.

A. Torey, S. Sasidharan, L. Y. Latha, S. Sudhakaran, S. Ramanathan, Pharm. Biol. 48 (2010) 1119-1123.

R. Farhoosh, G. A. Golmovahhed, M. H. H. Khodaparast, Food Chem. 100 (2007) 231-236. 